\title{
Synthesis and evaluation of thermally-responsive coatings based upon Diels-Alder chemistry and renewable materials $\uparrow$
}

\author{
Dahlia N. Amato, Gregory A. Strange, John P. Swanson, Anton D. Chavez, \\ Suzanne E. Roy, Kim L. Varney, Craig A. Machado, Douglas V. Amato \\ and Philip J. Costanzo*
}

A soybean based coating with thermally responsive Diels-Alder linkages has been prepared following an automotive 2-component formulation. The resulting coatings displayed the capability to be healed following physical deformation by a thermal stimulus, and such a material has significant potential for end users. Various curing agents were employed, and resulted in variation of scratch resistance and re-healablity. Different thermally responsive soybean resins were synthesized to have varying amounts reversible and nonreversible linkages when incorporated into the coating. Additionally, different isocyanates were added at differing ratios of $\mathrm{NCO}: \mathrm{OH}$ in search of the optimum coating. It was found through the analysis of rehealability, hardness, gloss, and adhesion that the optimal combination was an acetylated resin (no irreversible crosslinks) with 54\% reversible Diels-Alder linkages at an NCO : OH ratio of $5: 1$ using isophorone diiscocyanate. Materials were evaluated via differential scanning calorimetry (DSC), scratch resistance, Koenig hardness, gloss measurements, and topographical analysis.

Received 30th July 2013

Accepted 19th August 2013

DOI: 10.1039/c3py01024d

www.rsc.org/polymers the appropriate modification and viscosity, soybean oil resin can provide rigidity and strength comparable to chemical resin., ${ }^{2,7}$ This epoxidation of soybean oil is relatively easy and can obtain $90 \%$ conversion and selectivity. Gerbase has shown that epoxidized soybean oil has impeccable properties with thermal stability up to $300{ }^{\circ} \mathrm{C}$ and also found that the $T_{\mathrm{g}}$ and hardness increase with a higher number of epoxy groups in soybean oil. ${ }^{3,8}$

Opening epoxidized soybean oil with an acid is the most common way to make a soybean-based polyol. ${ }^{9}$ Other molecules such as organic and inorganic acids, alcohols, water or hydrogenation can be used to open the epoxide. ${ }^{5}$ After epoxidation and subsequent opening of the oxirane with an organic acid, a molecule of soybean oil on average has 4.4 hydroxyl groups upon it. Depending on the substituent attached to the organic acid one can also change physical properties such as $T_{\mathrm{g}}{ }^{6}$

The use and development of "click" chemistry has grown tremendously. ${ }^{10,11}$ In particular, Diels-Alder chemistry ${ }^{12,13}$ has been extensively utilized because of its simplicity and the introduction of a thermally responsive linkage, which can add further functionality to materials. Our research group and others have exploited the use of Diels-Alder chemistry to prepare thermally responsive materials, such as polymeric phase change materials, ${ }^{14}$ foams,${ }^{15}$ dynamic surfaces,${ }^{16}$ hybrid materials ${ }^{17-20}$ and rehealable polymers. ${ }^{21-25}$

The goal of this project is to generate soybean-based resin with thermally responsive Diels-Alder linkages. This resin can be incorporated to polyurethane two-component automotive formulations to prepare thermally responsive coatings.
California Polytechnic State University, Department of Chemistry and Biochemistry, 1 Grand Ave, San Luis Obispo, CA 93407-0402, USA. E-mail: pcostanz@calpoly.edu; Fax: +805-756-5500; Tel: +805-756-2692

$\uparrow$ Electronic supplementary information (ESI) available. See DOI: 10.1039/c3py01024d 


\section{Experimental}

\section{Methods and materials}

All materials were purchased from commercially available sources. ${ }^{1} \mathrm{H}$ NMR spectra were recorded on a $300 \mathrm{MHz}$ varian instrument in d-acetone, d-DMSO, or $\mathrm{CDCl}_{3}$. Chemical shifts, $\delta$ (ppm), were referenced to the residual solvent signal. Soybean oil derivatives are analogous to previously reported materials. ${ }^{7}$

\section{Synthesis of phenolic maleimide (1)}

To a $1000 \mathrm{~mL}$ Erlenmeyer flask equipped with a magnetic stir bar was added 4-aminophenol acid (44.5 g, $400 \mathrm{mmol}$ ) followed by acetone $(500 \mathrm{~mL})$ and the mixture was stirred at room temperature. In a $500 \mathrm{~mL}$ beaker, maleic anhydride (40 g, 400 $\mathrm{mmol})$ was dissolved in acetone $(300 \mathrm{~mL})$. This mixture was then slowly added to the Erlenmeyer flask and a yellow precipitate formed which was isolated by vacuum filtration and washed with acetone. The product was added to a $300 \mathrm{~mL}$ round bottom flask equipped with a magnetic stir bar followed by DMF $(50 \mathrm{~mL})$. To a $150 \mathrm{~mL}$ beaker equipped with a stir bar was added DMF (70 mL), followed by phosphorus pentoxide (21 $\mathrm{g}, 140 \mathrm{mmol}$ ) and fuming sulfuric acid (9 g, $91.8 \mathrm{mmol})$ (weighed out in a $10 \mathrm{~mL}$ graduated cylinder), and additional DMF $(20 \mathrm{~mL})$ which was used to rinse the sulfuric acid from the graduated cylinder into the beaker; this mixture was then added to the $300 \mathrm{~mL}$ round bottom flask which was sealed with a rubber septa and allowed to stir at $70{ }^{\circ} \mathrm{C}$ for $24 \mathrm{~h}$. The resulting viscous black liquid was then poured into a $4 \mathrm{~L}$ beaker containing ice water $(3 \mathrm{~L})$, precipitating a fine yellow powder that was isolated by vacuum filtration (55 g, 65\% yield). ${ }^{1} \mathrm{H}$ NMR ( $\delta, \mathrm{ppm}): 7.15$ (2H, d), $7.0(2 \mathrm{H}, \mathrm{s}), 6.9(2 \mathrm{H}, \mathrm{d})$.

\section{Synthesis of 4-(furfuryl oxycarbonyl) butanic acid (2)}

To a $500 \mathrm{~mL}$ round bottom flask equipped with a magnetic stir bar was added succinic anhydride $(5.00 \mathrm{~g}, 49.9 \mathrm{mmol})$ followed by a catalytic amount of dimethylaminopyridine (DMAP) $(0.300 \mathrm{~g})$. Toluene $(115 \mathrm{~mL})$ was then added and the solution was refluxed at $120{ }^{\circ} \mathrm{C}$ until the succinc anhydride and DMAP dissolved. Furfuryl alcohol (4.90 g, $49.9 \mathrm{mmol})$ was then added and the solution was allowed to stir under reflux for $24 \mathrm{~h}$ The toluene was then evaporated under vacuum leaving a dark residue which was dissolved in diethyl ether $(100 \mathrm{~mL})$ and washed with $\mathrm{HCl}(2.5 \%, 100 \mathrm{~mL}, 1 \times)$. The ether layer was collected and dried with magnesium sulfate, filtered and evaporated under vacuum yielding a dark liquid product $(8.96 \mathrm{~g}$, 90\% yield). ${ }^{1} \mathrm{H}$ NMR: $\delta$ (ppm) $7.45(1 \mathrm{H}, \mathrm{s}), 6.4(1 \mathrm{H}, \mathrm{d}), 6.35(1 \mathrm{H}$, t), $5.5(2 \mathrm{H}, \mathrm{s}), 2.15(4 \mathrm{H}, \mathrm{m})$.

\section{Synthesis of epoxidized soybean oil (ESBO)}

SBO (50.0 g, $54.7 \mathrm{mmol}$ ) was added to a 250 Erlenmeyer flask equipped with a stir bar followed by the slow addition of formic acid (16.65 g, $361.7 \mathrm{mmol}$ ) and cooled to $0{ }^{\circ} \mathrm{C}$. Hydrogen peroxide solution $(30 \%, 65.45 \mathrm{~g})$ was then slowly added to the flask and allowed to stir for 24 hours at room temperature. $\mathrm{Et}_{2} \mathrm{O}$ $(100 \mathrm{~mL})$ was then added to the flask to dissolve the oil and separate it from the aqueous peroxide/acid solution, which was removed and discarded and the ether layer was transferred to a $500 \mathrm{~mL}$ Erlenmeyer flask. Saturated sodium bicarbonate solution (50 mL increments) was then carefully added to the ether solution until gentle shaking of the mixture ceased to produce gas. The aqueous layer was then separated and discarded and the ether solution was washed with D.I. water $(50 \mathrm{~mL})$. The ether solution was then dried over magnesium sulfate and the ether was evaporated under vacuum yielding a clear, very slightly yellow colored oil (48 g, 88\% yield). ${ }^{1} \mathrm{H}$ NMR confirmed the epoxidation by the appearance of epoxide peaks at $\delta$ (ppm) 2.85, 2.95 and 3.1 and the disappearance of alkene peaks at $\delta(\mathrm{ppm}) 5.3$.

\section{Synthesis of furan soybean oil (FSBO)}

ESBO (14.8 g, $15 \mathrm{mmol}$ ) was added to a 250 round bottom flask equipped with a stir bar and $2(23.7 \mathrm{~g}, 120 \mathrm{mmol})$. The mixture was refluxed at $100{ }^{\circ} \mathrm{C}$ for 24 hours. The mixture was cooled and dissolved with $\mathrm{Et}_{2} \mathrm{O}(200 \mathrm{~mL})$ before washing with saturated $\mathrm{NaHCO}_{3}(\times 2,150 \mathrm{~mL})$ The organic layer was separated, dried with anhydrous sodium sulfate and filtered. Excess solvent was removed via rotary evaporation to yield a dark viscous oil $(20.2 \mathrm{~g}$, 76\%). Structure confirmed via $^{1} \mathrm{H}$ NMR: $\delta(\mathrm{ppm})$ furan peaks at $\delta$ (ppm) 6.35, 6.4, and 7.4.

\section{Acetylation of furan soybean oil (Ac-FSBO)}

To a $500 \mathrm{~mL}$ round bottom flask equipped with stir bar, FSBO $(17.8 \mathrm{~g}, 10 \mathrm{mmol})$ was added followed with acetic anhydride (4.2 g, $41 \mathrm{mmol})$, triethylamine $(4.4 \mathrm{~g}, 43 \mathrm{mmol})$, and THF $(25 \mathrm{~mL})$. The mixture was then refluxed at $70{ }^{\circ} \mathrm{C}$ for 24 hours. The mixture was cooled and THF was removed via rotary evaporation, before $\mathrm{Et}_{2} \mathrm{O}(100 \mathrm{~mL})$ was added followed by washing with brine $(\times 2,150 \mathrm{~mL})$. The organic layer was separated, dried with anhydrous sodium sulfate and filtered. Excess solvent was removed via rotary evaporation to yield a dark viscous oil (16.2 g, $83 \%)$. Structure confirmed via ${ }^{1} \mathrm{H}$ NMR: $\delta(\mathrm{ppm})$ by a new peak at $\delta(\mathrm{ppm}) 2.05$.

Table 1 Prepared TR-SBO materials

\begin{tabular}{|c|c|c|c|c|c|}
\hline \multirow[b]{2}{*}{ Sample } & \multirow{2}{*}{$\begin{array}{l}\% \\
\text { Furan }^{a}\end{array}$} & \multirow{2}{*}{$\begin{array}{l}\% \\
\text { Acetylated }^{a}\end{array}$} & \multirow{2}{*}{$\begin{array}{l}\% \\
\text { Diels-Alder }\end{array}$} & \multicolumn{2}{|c|}{ \# Of crosslinks ${ }^{c}$} \\
\hline & & & & Permanent & Reversible \\
\hline 1 & 50 & 0 & 100 & 4.4 & 4.4 \\
\hline 2 & 50 & 0 & 54 & 4.4 & 2.4 \\
\hline 3 & 50 & 0 & 30 & 4.4 & 1.3 \\
\hline 4 & 50 & 50 & 100 & 0 & 4.4 \\
\hline 5 & 50 & 50 & 54 & 0 & 2.4 \\
\hline 6 & 50 & 50 & 30 & 0 & 1.3 \\
\hline
\end{tabular}

${ }^{a}$ Percentage based upon 8.8 functional groups from 4.4 epoxides per soybean oil molecule as determined by ${ }^{1} \mathrm{H}$ NMR. ${ }^{b}$ Percentage based upon 4.4 furan groups per soybean oil molecule as determined by ${ }^{1} \mathrm{H}$ NMR. ${ }^{c}$ Value based upon 8.8 functional groups from 4.4 epoxides per soybean oil molecule as determined by ${ }^{1} \mathrm{H}$ NMR. 
Typical synthesis of thermally-responsive soybean oil (TRSBO)

Ac-FSBO (18 g, $9.3 \mathrm{mmol}$ ) was added to a $500 \mathrm{~mL}$ round bottom flask equipped with a stir bar followed by $1(7 \mathrm{~g}, 37 \mathrm{mmol})$ and THF (75 mL). The reaction mixture was stirred at $50{ }^{\circ} \mathrm{C}$ for two days. Solvent was removed under reduced pressure yielding a black viscous oil (21.6 g, 85\%). Structure confirmed via ${ }^{1} \mathrm{H}$ NMR: $\delta$ (ppm) 6.55, 6.4, 5.35, 3.05 and 2.95. The 54\% and 30\% DielsAlders soybean polyol was prepared by varying the amount of 2 . See Table 1 for a list of samples prepared.

\section{Differential scanning calorimetry (DSC) analysis}

A TA Instruments DSC Q1000 was utilized to observe potential endotherms within the TR-SBO samples caused by the incorporation of Diels-Alder linkages. All samples underwent a $5 \mathrm{~min}$ isotherm at $50{ }^{\circ} \mathrm{C}$ and were then heated to $175^{\circ} \mathrm{C}$ at a heating rate of $20{ }^{\circ} \mathrm{C} \mathrm{min}^{-1}$. After reaching peak temperature, the samples were cooled to $50{ }^{\circ} \mathrm{C}$ at a cooling rate of $10{ }^{\circ} \mathrm{C} \mathrm{min}^{-1}$. The typical sample masses were approximately $15 \mathrm{mg}$, which were sealed in aluminum hermetic pans.

\section{Coating formulation}

TR-SBO polyols, both acetylated and unacetylated with $100 \%$, $54 \%$, and $30 \%$ DA linkages, were incorporated into a 2-component automotive topcoat polyurethane coating system. Three isocyanates, Desmodur N3300, isophorone diisocyanate (IPDI) and hexamethylene diisocyanate (HMDI), were used to formulate three different coatings. All coatings were formulated without catalyst and with a $1: 1,3: 1$ and $5: 1$ ratio between $\mathrm{NCO}: \mathrm{OH}$. Each coating was drawn down on a $4 \times 6$ inch stainless steel panel with a $10 \mathrm{~mm}$ BYK draw down bar. For each coating at least three panels were prepared. The coating was placed in a $35^{\circ} \mathrm{C}$ oven for 30 minutes after letting it sit for approximately 15 minutes at room temperature. Typical part A formulation: soybean polyol (10 g), methyl amyl ketone $(5.77 \mathrm{~mL})$, xylene $(0.226 \mathrm{~mL}), n$-pentyl propionate $(0.162 \mathrm{~mL})$. Typical part B formulation: Desmodur N3300A (3.11 g), $n$-butyl acetate $(0.307 \mathrm{~mL})$.

\section{Control panel preparation}

A control coating without reversible crosslinks was made using FSBO as a polyol and using IPDI as an isocyanate to compare properties. Formulation of the coatings followed the previous procedure. Five different panels were prepared and the properties of the coating were also analyzed the same way.

\section{Crosscut adhesion test}

The adhesion testing followed ASTM D3359 and used a BYK crosscut test kit to make the crosscut. Scotch $3 \mathrm{M}$ no. 897 strapping tape was used for the pull-off portion of the test.

\section{Hardness}

The pendulum hardness test was used to compare the effect of retained solvents on the hardness of the film. A Byk Gardner pendulum hardness tester was used in the Konig mode. This mode measures the time taken for the pendulum amplitude to decrease from $6^{\circ}$ to $3^{\circ}$. Each coating's hardness was measured every two days over a 20 days period. Three data points were obtained for each panel.

\section{Gloss measurement}

Gloss measurements were taken as an average of three data points across the panel using a BYK Gardener Micro-TRI-Gloss

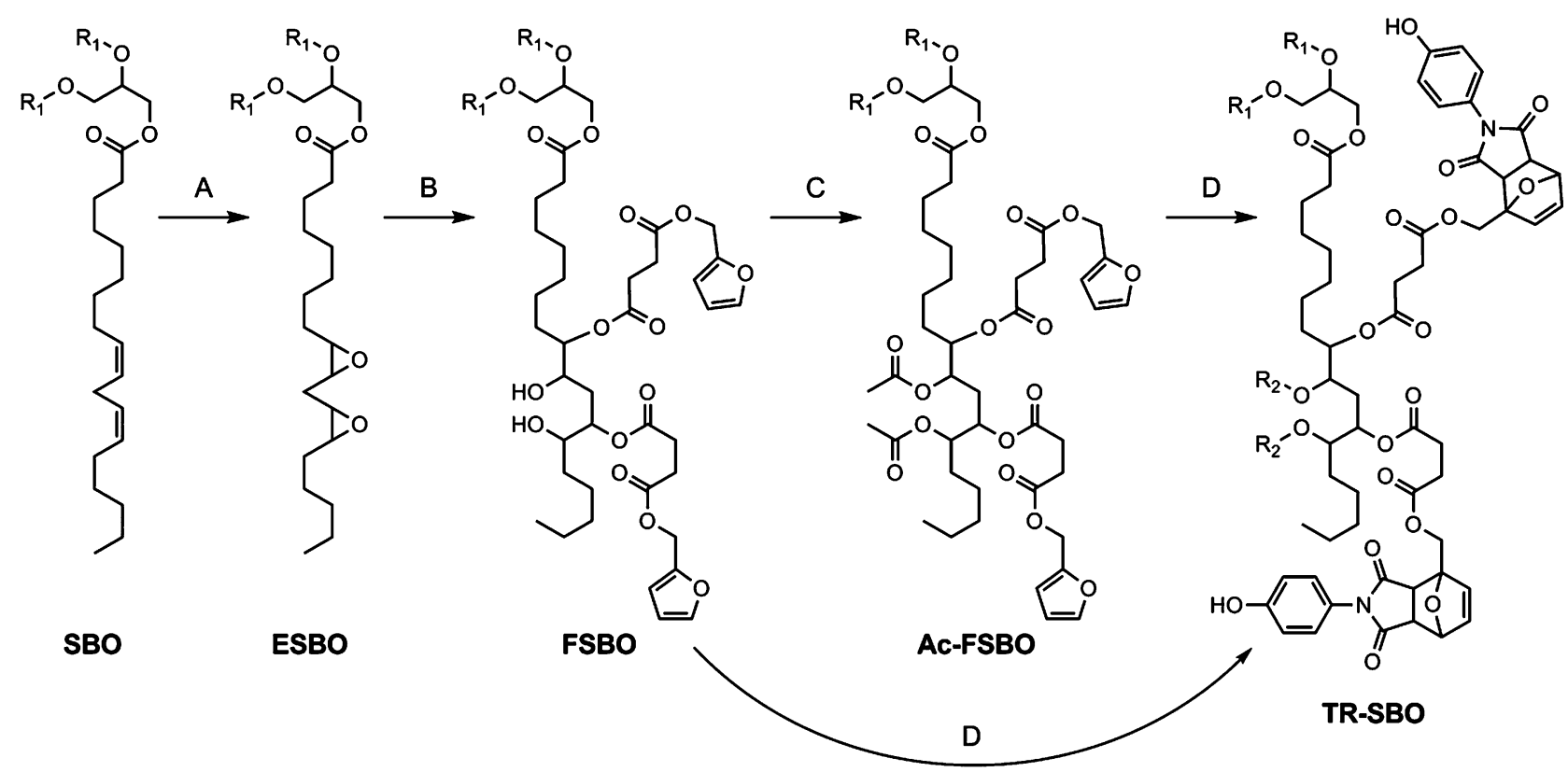

Scheme 1 Synthetic route for preparation of TR-SBO. $\mathrm{R}_{1}-$ Various fatty acids. Linoleic shown as primary. $\mathrm{R}_{2}-\mathrm{H}$ or Ac. Conditions: (A) $\mathrm{H}_{2} \mathrm{O}_{2}$, formic acid, RT, 24 h; (B) 2, neat, $100{ }^{\circ} \mathrm{C}, 24$ h; (C) acetic anhydride, Et ${ }_{3} \mathrm{~N}, \mathrm{THF}, 70{ }^{\circ} \mathrm{C}, 24 \mathrm{~h}$; (D) 1, THF, $50{ }^{\circ} \mathrm{C}, 2$ days. 
gloss meter at a $60^{\circ}$ angle. Variation of less than $3 \%$ were typically observed. ASTM D523-08 was followed for gloss measurements. The first measurement was taken after the coating had dried for four days. Then, the same panel was damaged using a mallet. A piece of sand paper was attached to the mallet to act as an abrasive component. A $3 \mathrm{~kg}$ weight on top of the mallet was added to maintain the amount of force applied to the panel. The mallet, sand paper, and weight combination were run across the panel three times. The second measurement of gloss was then recorded. The same panel was then heated for 30 seconds using the heat gun and cooled for 30 seconds. The heat gun reached a peak temperature of $95^{\circ} \mathrm{C}$ after 30 seconds. A third measurement of the panel was taken to measure the gloss after heating. The same process was done every four days up to a 20 days period. The best coating panels were also chosen to damage at the same site a second time to determine how the gloss changed with a second heating.

\section{ImageJ analysis}

The panel was horizontally cut with the Byk crosscut blade. The cut area was then scanned and the picture analyzed using ImageJ software. The cut area of the same panel was heated with the heat gun for 30 seconds and cooled for 30 seconds. The panel was again scanned and analyzed with ImageJ software. Image J was able to measure the intensity and the distance between each cut before and after heating.

\section{Results and discussion}

\section{TR-SBO: synthesis and initial characterization}

Following previously developed methodology, soybean oil was treated with formic acid and hydrogen peroxide to introduce epoxide functionality. ${ }^{7}$ Initial efforts attempted to introduce Diels-Alder functionality by opening the epoxide with 2 -furoic acid.

While this reaction was successful, the subsequent reaction with phenolic maleimide to prepare the Diels-Alder was not. Standard Diels-Alder reactions require an electron-rich diene and an electron-poor dieneophile. The placement of the carboxylic acid directly upon the furan ring deactivates it and inhibits the Diels-Alder reaction. This phenomenon has been previously reported. ${ }^{\mathbf{1 4}}$

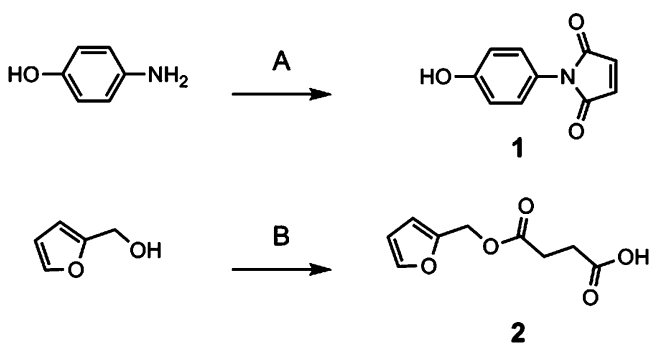

Scheme 2 Synthesis of small molecule components. Conditions: (A) (i) maleic anhydride, acetone, $\mathrm{RT}, 2 \mathrm{~h}$; (ii) $\mathrm{P}_{2} \mathrm{O}_{5}, \mathrm{H}_{2} \mathrm{SO}_{4}, \mathrm{DMF}, 70{ }^{\circ} \mathrm{C}, 12 \mathrm{~h}$; (B) succinic anhydride, DMAP, toluene, $120^{\circ} \mathrm{C}, 24 \mathrm{~h}$.
Scheme 1 illustrates the methodology utilized to prepare thermally-responsive soybean oil (TR-SBO). To maintain an electron-rich furan with a carboxylic acid functionality, furfuryl alcohol was treated with succinic anhydride in the presence of catalytic dimethyl aminopyridine (DMAP) to yield compound 2, Scheme 2. This reaction was able to be conducted in high yield and throughput with minimal workup. Employing 2, ESBO was easily functionalized and diene functionality was introduced to yield furan-soybean oil (FSBO). Upon opening of the epoxide, a latent alcohol functional group is created, and can be manipulated to alter the properties of the film. By leaving the alcohol functionality, a mixture of reversible (Diels-Alder crosslinks) and non-reversible crosslinks are present, which will dictate how the film reheals. Alternatively, FSBO was treated with excess acetic anhydride to acetylate the secondary alcohols preparing acetylated-furan soybean oil (Ac-FSBO), which will only contain reversible crosslinks. Finally, both FSBO and Ac-FSBO were treated with various equivalents of 1 to incorporate Diels-Alder adducts upon the soybean oil backbone to yield thermally-responsive soybean oil (TR-SBO). The variation in Diels-Alder adducts will manipulate the crosslink density of the

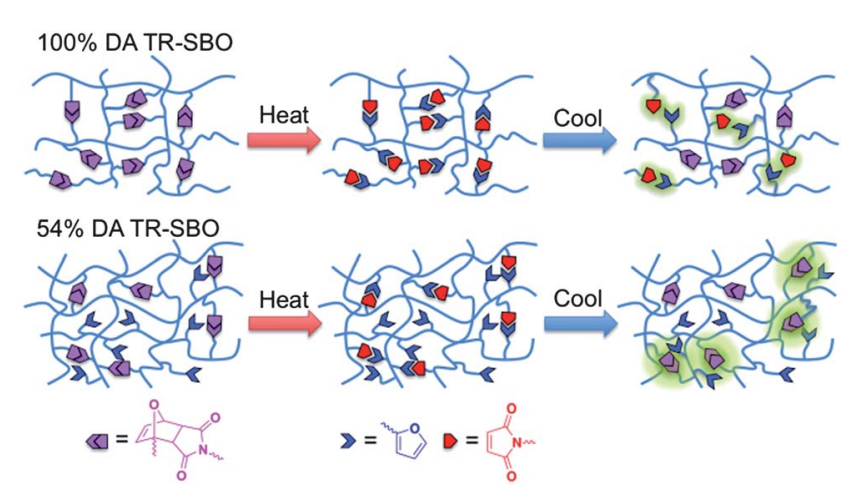

Fig. 1 Schematic representation of effect of non-stoichiometric Diels-Alder ratios upon crosslink density.

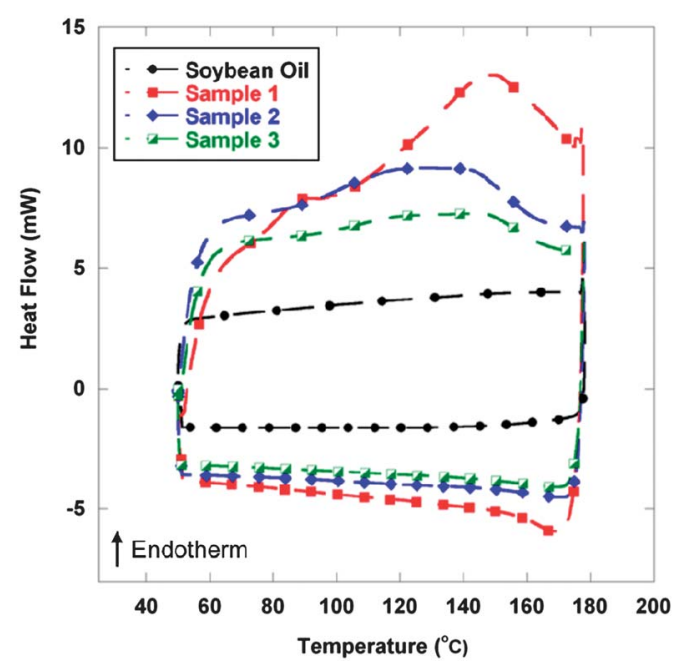

Fig. 2 DSC analysis of various TR-SBO materials with different amounts of Diels-Alder linkages. 


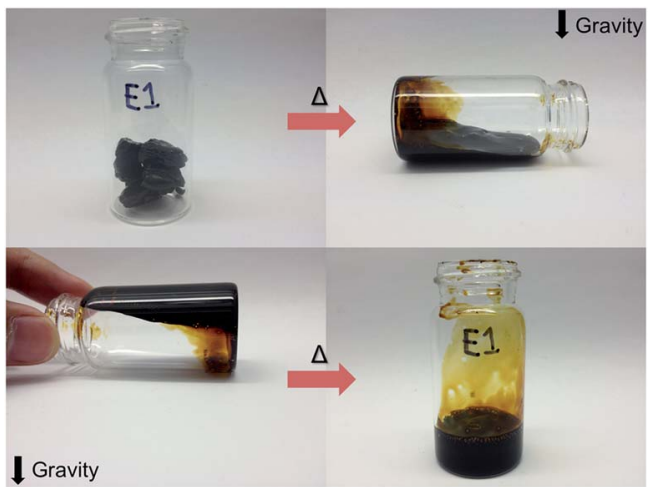

Fig. 3 Pictographs of TR-SBO (Sample 4) cured with IPDI in a one to one $\mathrm{NCO}: \mathrm{OH}$ ratio.

film and will influence how well the film is able to reheal. Previous efforts have demonstrated that $100 \%$ recovery of DielsAlder linkages is unlikely to occur during rehealing because the formation of new crosslinks can disrupt the orientation required for adduct formation. ${ }^{\mathbf{1 4 , 2 4}}$ By employing an excess of a functional group, the likelihood that the film will return to its initial crosslink density should increase. In the proposed system, a resin with 50\% Diels-Alder linkages will have a 50\% excess of furan functional groups. The initial film will have a number of dangling chain ends, but during thermal treatment, Diels-Alder adducts will be more likely to reform and film will maintain a constant number of dangling chains, Fig. 1.

Fig. 2 displays differential scanning calorimetry (DSC) analysis of various TR-SBO samples and soybean oil. A large endotherm is present for TR-SBO samples indicating the retro Diels-Alder reaction, while the soybean displays no such thermal behaviour. The magnitude of the endotherm corresponds to the percentage of Diels-Alder linkages present in the resin.

To demonstrate the reversible nature of the Diels-Alder linkages within the resin, TR-SBO was treated with isophorone diisocyanate (IPDI) in a one to one molar equivalency of $\mathrm{NCO}: \mathrm{OH}$ to yield cured plaques. As a control, FSBO was also cured into plaques with IPDI in a one to one molar equivalence of NCO : OH. Fig. S1† displays images of the prepared gels in DMF after $24 \mathrm{~h}$ at RT indicating that the materials are well cured and insoluble. After heating at $120^{\circ} \mathrm{C}$ for $24 \mathrm{~h}$, TR-SBO plaques have completely dissolved due to cleavage of the Diels-Alder linkages while the control plaques remained intact. To demonstrate the repeatability of this process, TR-SBO was placed into a scintillation vial and heated. As seen in Fig. 3, the TR-SBO easily flowed upon exposure to thermal stimulus and upon removal of the heat, Diels-Alder linkages reformed and the physical integrity of the plaque was reinstated. The vial was then rotated and the experiment repeated indicating the reversibility and repeatability of cleaving and reforming Diels-Alder linkages.

\section{TR-SBO films: curing agent, hardness and adhesion}

TR-SBO resins were then incorporated into a standard 2component automotive topcoat polyurethane coating system.

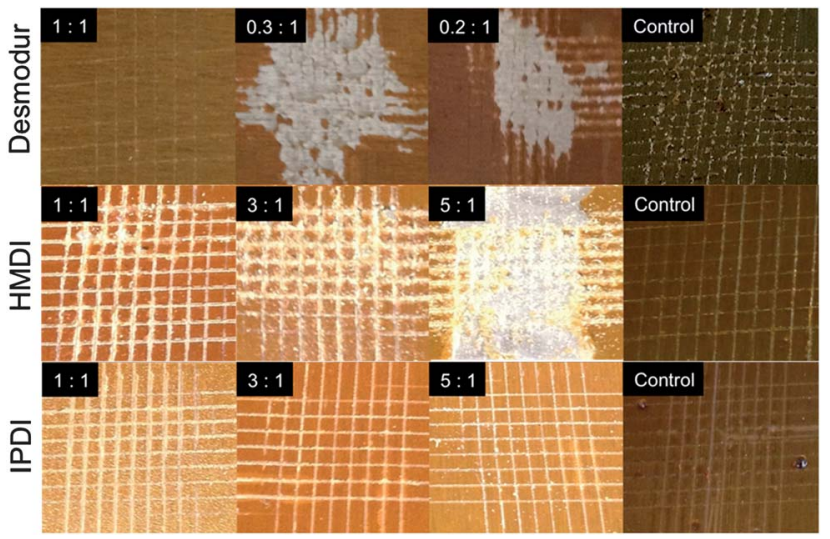

Fig. 4 Pictographs of TR-SBO topcoat resins (Sample 4) after crosscut. Analysis was conducted 7 days after film was initially prepared.

Drawdowns were prepared with a $10 \mathrm{~mm}$ BYK draw down bar upon stainless steel plates. Cross cut analysis followed ASTM D3359 and used a BYK crosscut test kit to make the crosscut.

Scotch 3M no. 897 strapping tape was used for the pull-off portion of the test. The test was done on day six after the coating had cured. Fig. 4 displays images of panels with various curing agents and ratios of NCO : OH for TR-SBO materials with only reversible resin crosslinks. Common coating formulations employ excess isocyanate to increase film hardness and adhesion. IPDI displayed the highest adhesion regardless of the NCO : $\mathrm{OH}$ ratio. Desmodur and HMDI contain only primary isocyanates while IPDI contains a primary and secondary isocyanate, indicating that the speed of the reaction will influence the adhesion of the film to the substrate. IPDI also displayed the highest hardness of three curing agents, Fig. S2. $\dagger$ We hypothesize that faster curing films have decreased

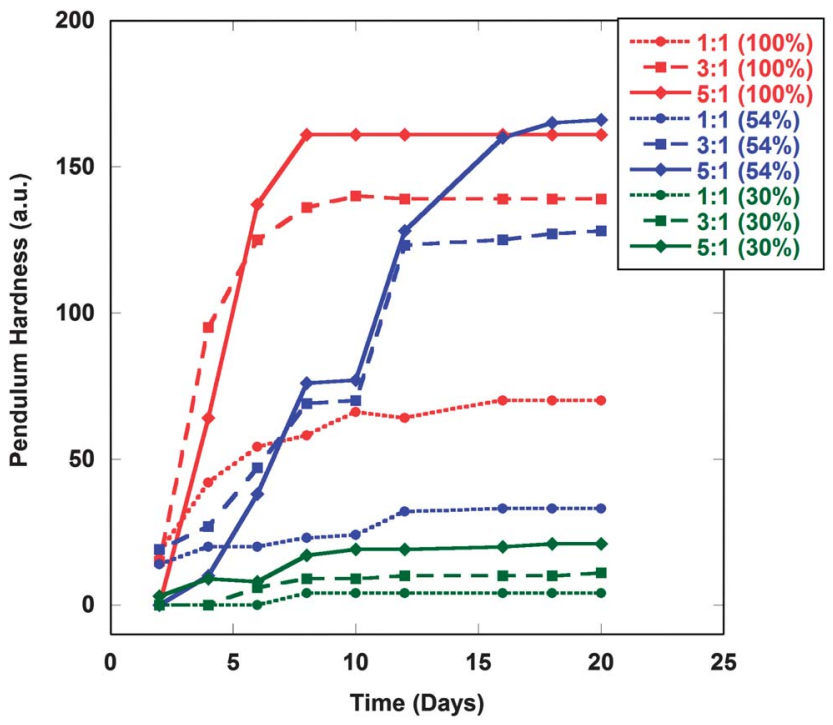

Fig. 5 Hardness measurements of TR-SBO films (Samples 4, 5 and 6) cured with various $\mathrm{NCO}: \mathrm{OH}$ ratios. IPDI was employed as a curing agent for all films. 


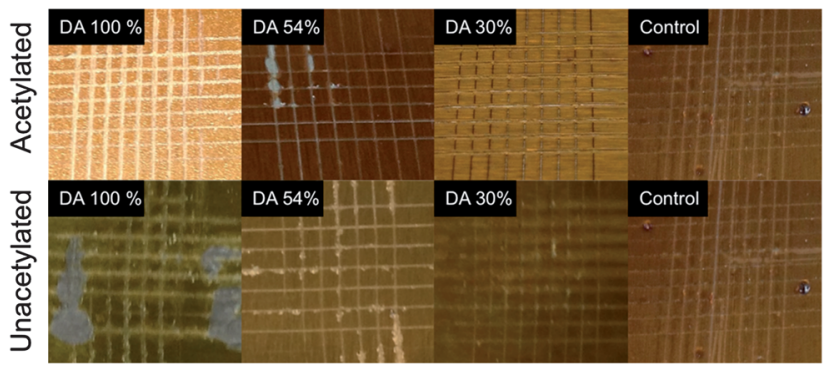

Fig. 6 Pictographs of TR-SBO topcoat resins after crosscut. IPDI was employed as a curing agent for all films. Analysis was conducted 7 days after film was initially prepared.

opportunity to interact with the substrate and result in decreased adhesion.

Upon recognizing IPDI as a superior curing agent, the ratio of NCO : $\mathrm{OH}$ and the percentage of Diels-Alder adducts present were explored. As previously mentioned higher NCO : OH ratios result in harder films which can be observed in Fig. 5 as expected. Fig. 5 also examines the effect of Diels-Alder adducts within the resin. As expected, by decreasing the number of Diels-Alder adducts the number of dangling chains within the matrix increase, which lowers the hardness of the film.

Next, the effect of reversible and non-reversible resin crosslinks were investigated by employing non-acetylated soybean oil resins. As expected, the non-acetylated displayed harder films, Fig. S3. $\uparrow$ By increasing the crosslink density, the hardness of the films increased. Fig. 6 compares crosscut analysis of films with and without non-reversible linkages and with various concentrations of Diels-Alder adducts. For these samples, IPDI was employed in a one to one $\mathrm{NCO}: \mathrm{OH}$ ratio. Here, the acetylated resins displayed improved adhesion. The non-acetylated resins cure faster resulting in decrease substrate interaction and poor adhesion. By decreasing the content of the Diels-Alder adducts, the curing rate is decreased which improves adhesion. These results illustrate the need to balance multiple properties in the

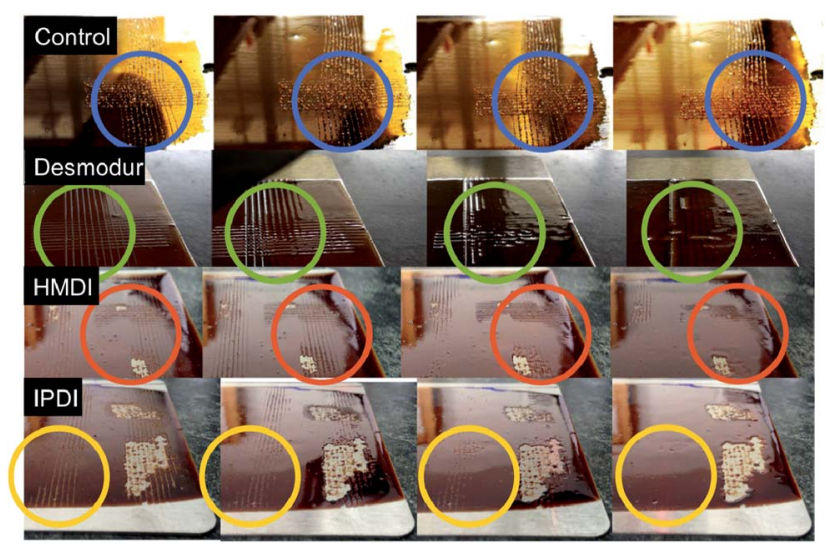

Fig. 7 Pictographs of control film (FSBO) and TR-SBO topcoat resins (Sample 4) prepared with various curing agents after deformation and repeated exposure to thermal treatment. IPDI was employed as a curing agent for the control film of FSBO. Analysis was conducted 3 days after film was initially prepared.

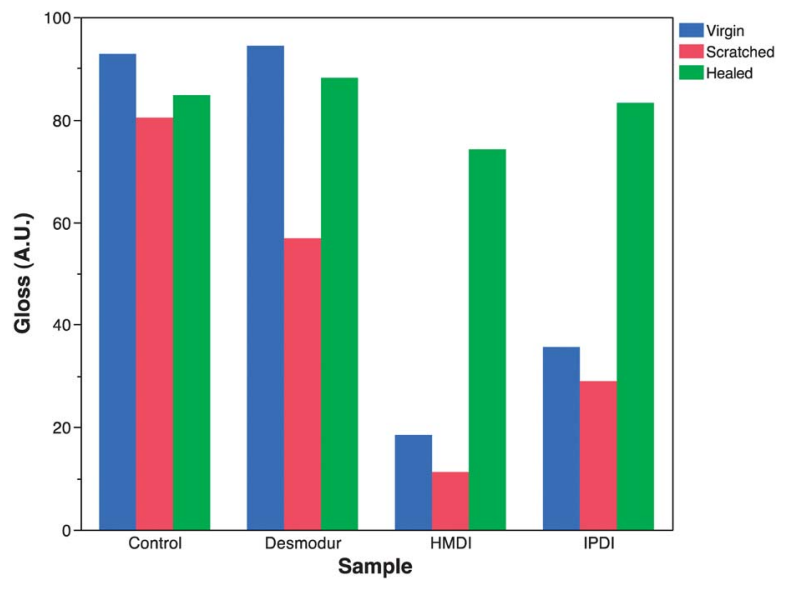

Fig. 8 Gloss measurements of control film (FSBO) and TR-SBO topcoat resins (Sample 4) prepared with various curing agents in a one to one $\mathrm{NCO}: \mathrm{OH}$ ratio after deformation and exposure to thermal treatment. IPDI was employed as a curing agent for the control film of FSBO. Analysis was conducted 12 days after film was initially prepared.

development of an ideal coating. While non-acetylated resins displayed increased hardness, they also displayed poor adhesion.

\section{TR-SBO films: rehealability}

Finally, rehealability experiments were conducted by deforming a film via crosscut or abrasion follow by a 30-90 s exposure to heat gun on high. A peak temperature of $95{ }^{\circ} \mathrm{C}$ was reached after 30 seconds. Care was taken to evenly heat the substrate as much as possible to avoid any type of degradation. Fig. 7 displays time lapse images of films during exposure. The TRSBO containing films exhibit rehealability by flowing after deformation. The control film does not demonstrate any response to thermal stimulus. While this approach provides qualitative analysis, a quantitative approach was desired and gloss measurements were utilized following ASTM D523-08. Gloss is a measurement of the reflection of incident light. Smoother surfaces will result in specular reflection, while

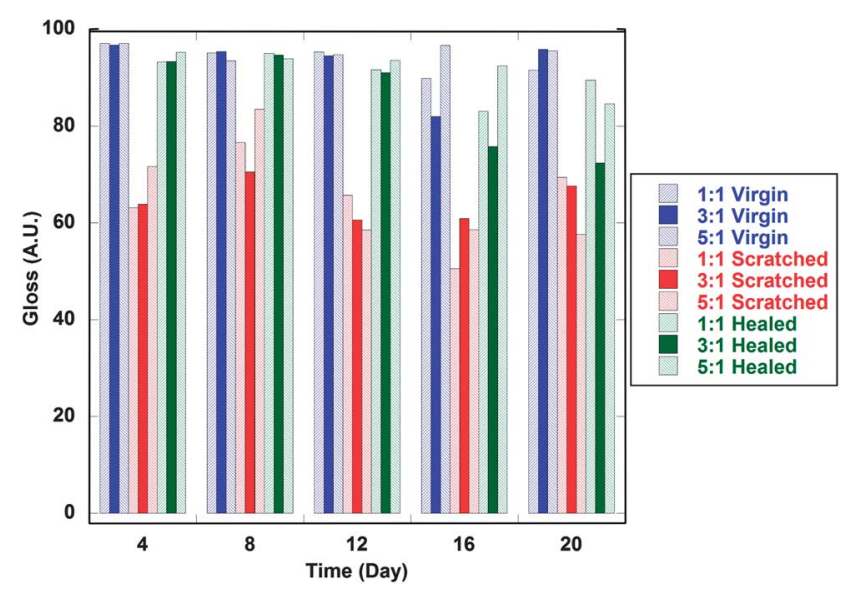

Fig. 9 Gloss measurements of TR-SBO topcoat resins (Sample 5) prepared with IPDI and various $\mathrm{NCO}: \mathrm{OH}$ ratios after deformation and exposure to thermal treatment. 

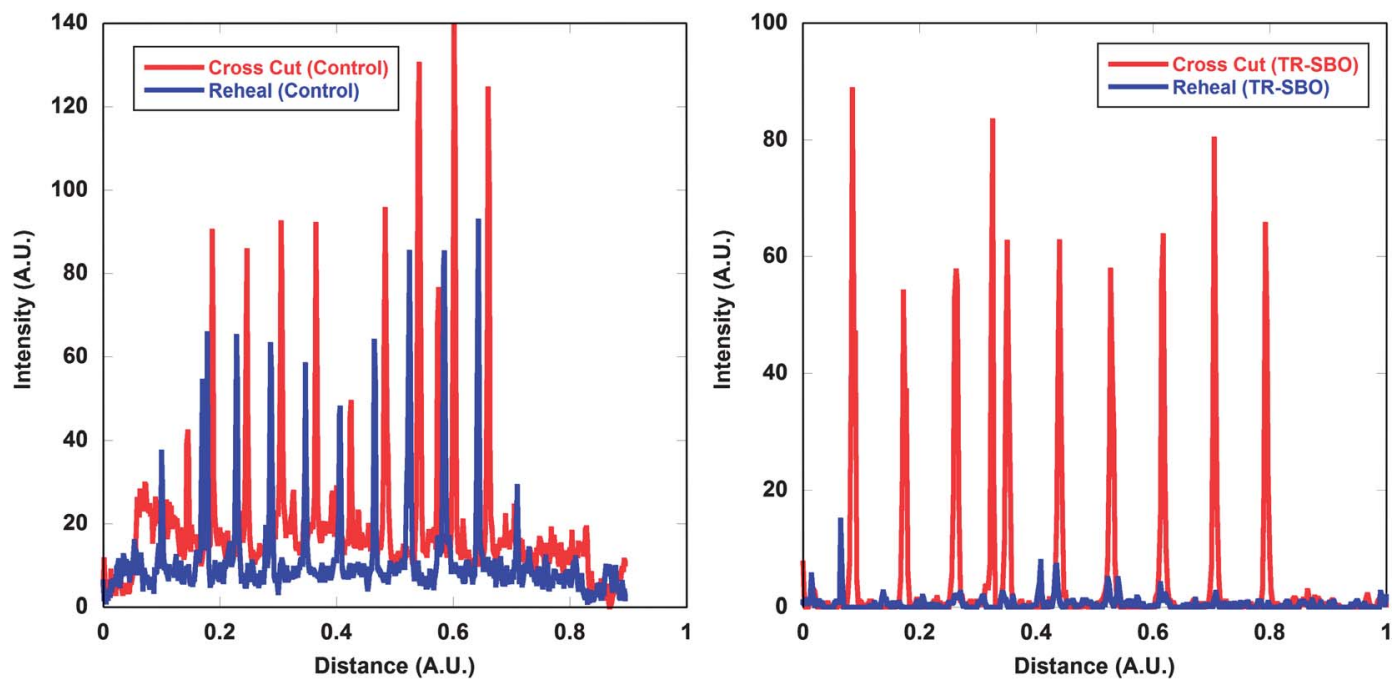

Fig. 10 ImageJ analysis of control film (FSBO) and TR-SBO topcoat resin (Sample 5) using IPDI as a curing agent in a five to one NCO : OH ratio. Analysis was conducted 12 days after film was initially prepared.

rough surfaces will result in diffuse reflection. Here, an initial measurement was collected. The film was damaged in a repeatable fashion, and gloss was recorded again. For TR-SBO films, damaged substrates were exposed to a heat gun for $30 \mathrm{~s}$ and then a final gloss measurement was taken. Fig. 8 displays gloss measurements of four different samples varying the curing agent and the resin. There are three main observations from this analysis. First, the control sample does not display rehealability. Second, TR-SBO resin exhibited a huge increase in gloss after rehealing regardless of the curing agent. Third, initial gloss measurements can vary greatly based upon the curing agent. We hypothesize that the variation in curing rate caused by the different curing agents creates a non-uniform surfaces which decrease gloss. After thermal treatment, a more thermodynamic surface equilibrium is reached and gloss increases. Considering previous experimental data, IPDI was chosen as the curing agent. Fig. 9 displays gloss measurements for various NCO : OH of IPDI for 54\% Diels-Alder. Fig. S4 $\dagger$ displays gloss measurement for 100 and 30\% Diels-Alder. In all cases, it shows that increasing the $\mathrm{NCO}: \mathrm{OH}$ ratio increases the initial gloss measurement. It also indicates that excess furan
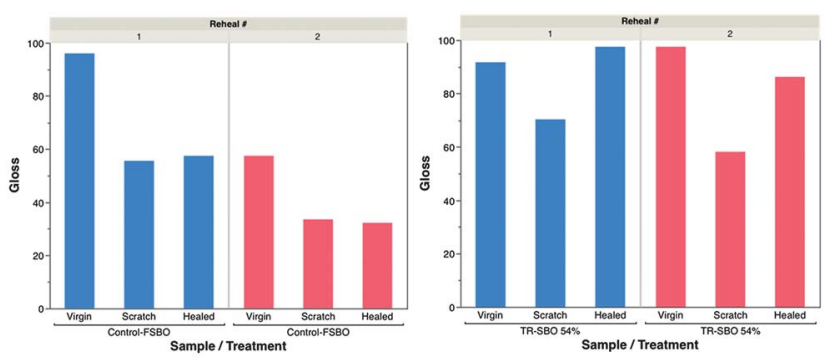

Fig. 11 Gloss measurements of control film (FSBO) and TR-SBO topcoat resin (Sample 5) prepared using IPDI as a curing agent in a five to one $\mathrm{NCO}: \mathrm{OH}$ ratio. Analysis was conducted 12 days after film was initially prepared. increases Diels-Alder formation by the larger increase in gloss observed when comparing 30, 54 and 100\% Diels-Alder adducts. As previously discussed, network formation can inhibit orientation required for Diels-Alder formation. By increasing the concentration of furan functional groups within the resin, it appears to increase the formation of Diels-Alder adducts after thermal treatment as seen by the increase in gloss measurement, Fig. 1 . In the $100 \%$ Diels-Alder samples, there are a minimum number of dangling chains present within the matrix. After thermal treatment, reformation of all Diels-Alder linkages is unlikely, resulting in a net increase in the number of dangling chains present in the matrix. In the $54 \%$ Diels-Alder samples, the initial amount of dangling chains present is larger than the $100 \%$ Diels-Alder sample. But after thermal treatment, the excess furan functionality increases Diels-Alder formation and results in a zero net change of dangling chains within the matrix. After considering the balance of curing rate, hardness, initial gloss and rehealability an optimum formulation was determined to by an acetylated TR-SBO with $54 \%$ DA and IPDI as the curing agent.

To further quantify the rehealability of the film, ImageJ analysis was utilized to measure the topographical outline of film before and after rehealing occurred. The observed intensity is related to the contrast of the substrate versus the sample. After deformation of the film, the aluminium substrate is exposed which can be observed as contrast. The peak intensity relate to the cracks in the film. As seen in Fig. 10, the control sample displays an identical topography before and after exposure to a thermal stimulus, whereas the TR-SBO film, displays a great decrease in the surface roughness after thermal treatment. Fig. $\mathrm{S} 5 \dagger$ displays pictographs of the film before and after thermal treatment.

Fig. 11 displays gloss measurements after repeated deformation and healing. Deformation of the control film results in catastrophic loss of gloss. After thermal treatment, the TR-SBO film is able to reclaim initial gloss after repeated damage. 


\section{Conclusions}

We have demonstrated the ability to prepare thermallyresponsive film based upon a renewable resource, soybean oil that is able to be rehealed repeatedly. Physical properties such as hardness, gloss and rehealablity were explored by manipulating variables such as the presence/absence of non-reversible linkages, percentage of reversible linkages and ratio of NCO : OH. A balance between film hardness, initial gloss, adhesion and rehealability can be achieved by employing an acetylated resin with 54\% Diels-Alder adducts and an IPDI curing agent.

\section{Acknowledgements}

This material is based upon work supported by the National Science Foundation under CHE - 1213331.

\section{Notes and references}

1 P. P. Meyer, N. Techaphattana, S. Manundawee, S. Sankeaw, W. Junlakan and C. Tongurai, Int. J. Sci. Technol., 2008, 13, 1. 2 F. Li, M. V. Hanson and R. C. Larock, Polymer, 2001, 42, 1567. 3 B. K. Sharma, J. M. Perez and S. Z. Erhan, Energy Fuels, 2007, 21, 2408.

4 M. Ionescu, Z. S. Petrovic and X. Wan, J. Polym. Environ., 2007, 15, 237.

5 A. Guo, I. Javni and Z. S. Petrovic, J. Appl. Polym. Sci., 2000, 77, 467.

6 M. Bahr and R. Muthaupt, Green Chem., 2012, 14, 483.

7 C. K. Hong and R. P. Wool, J. Appl. Polym. Sci., 2005, 95, 1524.

8 A. e. Gerbase, C. L. Petzhold and A. P. O. Costa, J. Am. Oil Chem. Soc., 2002, 79, 797.
9 R. e. Clemente and e. B. Cahoon, Plant Physiol., 2009, 151, 1030.

10 H. C. Kolb, M. G. Finn and K. B. Sharpless, Angew. Chem., Int. Ed., 2001, 40, 2004.

11 R. K. Iha, K. L. Wooley, A. M. Nystrom, D. J. Burke, M. J. Kade and C. J. Hawker, Chem. Rev., 2009, 109, 5620.

12 W. Carruthers, Cycloaddition Reactions in Organic Synthesis, Oxford, U. K., 1990.

13 F. Fringuelli and A. Taticchi, Dienes in the Diels-Alder Reaction, John Wiley \& Sons, New York, 1990.

14 J. P. Swanson, S. Rozvadovsky, J. E. Seppala, M. E. Mackay, R. E. Jensen and P. J. Costanzo, Macromolecules, 2010, 43, 6135.

15 J. R. Mcelhanon, E. M. Russick, D. R. Wheeler, D. A. Low and J. H. Aubert, J. Appl. Polym. Sci., 2002, 85, 1496.

16 P. T. Dirlam, G. A. Strange, J. A. Orlicki, E. D. Wetzel and P. J. Costanzo, Langmuir, 2010, 26, 3942.

17 P. J. Costanzo and F. L. Beyer, Macromolecules, 2007, 40, 3996.

18 P. J. Costanzo, J. D. Demaree and F. L. Beyer, Langmuir, 2006, 22, 10251.

19 Y. Imai, H. Itoh, K. Naka and Y. Chujo, Macromolecules, 2000, 33, 4343.

20 P. J. Costanzo and F. L. Beyer, Chem. Mater., 2007, 19, 6168. 21 X. Chen, F. Wudl, A. K. Mak, H. Shen and S. R. Nutt, Macromolecules, 2003, 36, 1802.

22 R. Gheneim, C. Perez-Berumen and A. Gandini, Macromolecules, 2002, 35, 7246.

23 Y. Zhang, A. A. Broekhuis and F. Picchioni, Macromolecules, 2009, 42, 1906.

24 R. J. Sheridan and C. N. Bowman, Polym. Chem., 2013, 4, 4974.

25 Y.-L. Liu and T.-W. Chuo, Polym. Chem., 2013, 4, 2194. 